\title{
Factors associated with exclusive breastfeeding practices in Debre Berhan District, Central Ethiopia: a cross sectional community based study
}

\author{
Maeza Mitiku Asfaw ${ }^{1}$, Mesele Damte Argaw $^{2^{*}}$ and Zelalem Kebede Kefene ${ }^{3}$
}

\begin{abstract}
Background: Globally, an estimated 6.3 million children under-five years of age died in the year 2013. To reduce the burden of morbidity and mortality of infants, Ethiopia adopted the World Health Organization (WHO) recommendation of exclusive breastfeeding (EBF) for the first six months of life. The objective of this study was to assess factors associated with EBF practices among mothers who have an infant aged below 12 months in Debre Berhan District, Ethiopia.

Methods: In this study we employed a cross sectional community based quantitative survey method, and data were collected from January through April 2014. Univariate statistical analysis was used to describe variables using frequencies and percentages. Multivariable logistic regression model was developed; the factors associated with EBF practice were identified.

Result: We enrolled 634 mothers with their index infant aged under 12 months. Four hundred thirty five $(68.6 \%$; $95 \%$ Cl: $64.9 \%, 72.2 \%$ ) mothers practiced EBF to six months. In this study $83.4 \%$ of mothers were knowledgeable with the recommended duration of EBF. About $97.5 \%$ of mothers had a positive attitude towards EBF practice. Mothers from rural places were 4.54 times likely to EBF than mothers residing in urban areas Adjusted Odds Ratio (AOR 4.54; $95 \%$ Cl: $2.64,7.81, p=0.001$ ). The odds of mothers aged 25 to 35 years to practice EBF was up to 8.9 times more than mothers aged less than 25 years (AOR 8.99; $95 \% \mathrm{Cl}: 4.56,17.73, p=0.001$ ). The odds of mothers who didn't receive infant feeding counselling was 0.42 times less likely to practice EBF than those who received Counselling services (AOR 0.42; $95 \%$ Cl: $0.24,0.73, p=0.002$ ). Employed mothers were found to be 0.36 times less likely to practice EBF than housewives (AOR 0.36; $95 \% \mathrm{Cl}: 0.18,0.73, p=0.005)$. Household income did not show a statistically significant association with EBF.

Conclusions: The knowledge and attitude of mothers towards EBF was found to be very high. In this study, two thirds of mothers practiced exclusive breastfeeding. Improving access to information on recommended infant feeding during routine maternal and child health services is recommended. It is important to encourage EBF among the young, employed and urban mothers through proper counselling and mother friendly work environment.
\end{abstract}

\section{Background}

Globally, there has been progress in improving child survival. Though the world promised to reduce child death by two thirds by 2015 from the level recorded in 1990, in the last two decades the under-five deaths was reduced by half in 2013, from 12.7 to 6.3 million. To keep the momentum of these achievements nearly 180 governments

\footnotetext{
* Correspondence: mdamte5@gmail.com

${ }^{2}$ Private Health Sector Program, P O Box 2372, Code 1250 Addis Ababa, Ethiopia

Full list of author information is available at the end of the article
}

have pledged to scale up efforts to accelerate the reduction in maternal, neonatal and child deaths as part of achieving the Millennium Development Goal (MDG) [1, 2].

Sub-Saharan Africa (SSA) continues to shoulder the greatest burden where the under-five deaths are 15 times higher than deaths in an average high income country [1]. Ethiopia is one of the countries with the highest infant mortality rate (59/1000 live birth) [3]. The country has developed a strategic document to systematically address issues regarding child survival, infant and young children feeding $[4,5]$. To reduce the burden of morbidity and

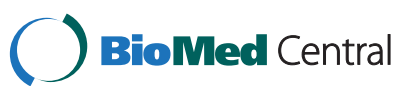


mortality of infants, Ethiopia adopted the World Health Organization (WHO) recommendations to provide exclusive breastfeeding (EBF) for infants in the first 6 months of life [6].

The trends of EBF from 1995 to 2010 were estimated using global database of 140 countries from United Nations Children's Fund and they found that in spite of the facts known about EBF, it was not widely practiced in many developing countries [7]. The situation in Ethiopia is not different from many countries. Evidence revealed that though $96 \%$ of children had ever breastfed in their lifetime [8] a significant proportion of them had delayed initiation of breastfeeding [9] or were given a prelacteal meal, and were subjected to early weaning with associated health risks for the infants.

Several studies documented that the prevalence of EBF in Amhara Region of Ethiopia remains close to 50 per cent [10-13]. Socio-demographic characteristics including maternal age, educational status, employment and household income were identified as factors influencing EBF practice [10-15]. The routine maternal and child health services (antenatal, delivery, postnatal) and infant feeding counselling were positively associated with EBF. Psycho-social support offered for mothers, general feeding habit of the community and gender were found to have significant associations with better EBF practices [10, 16-19]. Mothers with a desirable knowledge level, positive attitude and experiences of EBF were identified as immediate determinants for maintaining EBF practice $[11,13,17,20]$. These factors have been identified as a predictor for EBF practice with various levels of incidence and strengths. Hence, it is difficult to generalize the findings for other similar populations.

In 2003 the Federal Ministry of Health of Ethiopia (FMOH) and development partners designed Health Extension Program (HEP). The main purpose of the HEP includes production of health at household level and improving access to basic health services at the community and household level. Its goal is to promote appropriate health behaviour and outcomes of maternal, neonatal and child health services [21, 22]. The community health program is led and executed by Health Extension Workers (HEWs) and the support they received from community health agents like Health Development Army (HAD) [23]. HEWs and the HDAs are expected to improve the level of awareness about newborn, infant and child feeding issues in the community. One of the goals illustrated in the strategic document is to improve the rate of exclusive breastfeeding to increase from $49 \%$ in 2010 to $70 \%$ by the year 2015 [20].

Debre Berhan District has executed the complete set of HEP. The main focus of the district was to further reduce the infant mortality rate. The district wants to assess the infant EBF practice of the mother and factors influencing for the desired practice [24]. This community based cross sectional study was conducted in Debre Berhan District, in North Shoa Administrative Zone of Amhara Region. The aim of the study was to determine the knowledge, attitude and practice towards EBF among mothers who have children aged below 12 months and to explore factors influencing EBF practice. The purpose of the study was to assess the incidence of EBF in Debre Berhan District and recommend appropriate interventions to improve its outcome. The following hypotheses were put forth: there was no difference on EBF practice based on socio-demographic characteristics of mothers. The incidence of EBF for the first six months was low among mothers having children under twelve months of age.

\section{Definition of terms}

According to WHO [6], exclusive breastfeeding is the practice of feeding breast milk only, including expressed breast milk, to infants and excluding water, other liquids, breast milk substitutes, and solid foods. Vitamin drops, minerals, oral rehydrating solution (ORS) and medicines may be given. Prelacteal feedings are defined as feedings that are given to infant before they are put on the breast for the first time. HEWs: A community level health worker trained for one year at an undergraduate level to deliver preventive, promotive and curative health services, such as maternal and child health services [21]. Health Development Army: In a network of up to 5 families each, one of the families, who is an innovator or front liner in practicing health behaviour, leads the network and gradually influences the rest of the households to acquire skill and changes in attitudes towards healthy behaviour. The network is technically supported by the HEWs, who facilitate and follow up regularly conversations within the community. Kebele: The smallest administrative unit with 5000 people [23].

\section{Methods}

\section{Study setting}

The study was conducted in Debre Berhan District, one of the 177 districts of Amhara Region of Ethiopia. The district is located $125 \mathrm{~km}$ to the North of Addis Ababa, the capital city of Ethiopia. Debre Berhan district has nine kebeles, of which five kebeles are categorized as urban and the remaining four are rural. Based on the projection of the 2007 population census in the year 2014, the district has an estimated 84,920 (41,187 males and 43,733 females) inhabitants, of which 2,649 are infants. There are ten health extension posts and five health centres with at potential health service coverage of $100 \%$ [24].

\section{Study design and sample size}

A cross sectional community based survey was conducted among mothers with their index infant age less than 
12 months from January through April 2014, in Debre Berhan District, of North Shoa Administrative Zone, in Amhara Region. The sample size was determined using Cochran's formula [25]:

$$
n i=Z^{2}{ }_{\alpha} / \frac{2 p(1-p)}{d^{2}}
$$

Where, ni is the sample size, $\mathrm{Z}$ is standard normal variable at $95 \%$ Confidence Interval (1.96), P is (0.52) the proportion of mothers who practiced exclusively breastfeeding for their infants in Ethiopia [8], $d$ is the marginal error (0.05), design effect (1.5) and contingency for non-response (0.10).

\section{Sampling}

First we selected four ( 2 urban and 2 rural) out of nine kebeles, the smallest administrative units, using lottery methods. Then, we conducted population census in these kebeles and identified 1177 mother with index infant aged less than 12 months. Sampling frame was developed and study subjects were selected every other household with systematic random sampling techniques. During data collection 53 mothers and their index infants were replaced by the next study subject due to incomplete responses and missing basic information. Data were collected from 634 mothers with their index infant aged less than 12 months. At the end of the data collection the recommended infant feeding practices were delivered to all mothers as key health messages.

In this study we included mothers who lived in the study area for more than six months, with one infant at the time of the survey and who have no restrictions to breastfeed their index infant due to serious medical or surgical health conditions. Furthermore, mothers who were pregnant at the time of the survey, were excluded. In the case of having two or more mothers with infants in the household we selected the one with younger age infant.

\section{Measures}

The data were collected using interview method by pretested questionnaires. The questionnaire was prepared first in English and then translated into Amharic. To maintain the consistency of the tool it was back translated to English by two different public health professionals. The data collectors and their supervisors attended the necessary training on the objective of the study, data collection techniques, procedures and instruction to complete the questionnaires. The tool was pretested with 70 mothers who had infants under one year old in Basona Worana District of North Shoa Administrative Zone, which was not the part of our study area. Then the data collection tools were amended and rearranged to accommodate the desired data for the study.
The data were collected using a tool designed and piloted by the researchers [8]. The data were collected by volunteers who have completed $10^{\text {th }}$ grade education. The supervisors were two health professionals with a Masters degree in Public Health. The data collection team were trained and the data collection process was supervised by the researchers.

The questionnaires have socio-demographic information of mothers and infants, knowledge, attitude and practice of mothers on exclusive breastfeeding. In this study the dependent variable was EBF Practice [6] for the first six month of the index infant by mothers. In the regression analysis EBF practice was coded as ' 1 ' while ' 0 ' was coded for non-EBF practices.

The independent variable were age, educational status, residence, marital status of mother, household income, occupation, family size, birth order, sex of infant, place of delivery, antenatal and postnatal service uptake. To estimate the knowledge of mothers on EBF, we asked mothers about ideal duration of EBF and the time to wean off infants. In this study, those mothers who correctly identified the duration of EBF as six months were considered as knowledgeable. Five questions were presented to mothers to identify their attitudes towards EBF practice. Mothers who want to EBF their next baby or those who encourage their peers to do so were considered to have a favourable attitude towards EBF. The practice of mothers were measured based on their report on initiation time of breastfeeding, provision of colostrum, and the duration of EBF for the index infant. Mothers who fed their infant only breast milk for the first six months of life were considered as having an ideal practice.

The age of mothers were categorized into three groups i.e. $<25,25-35$ and $>35$ years. The younger age group was taken as a reference population in the regression analysis. Religion of mothers was coded as ' 0 ' for Christian and ' 1 ' for Muslim. Urban and rural residences of mothers were coded as ' 0 ' and ' 1 ' respectively. With regard to educational status of parents those who could not read and write were coded ' 0 ' while the rest were coded as ' 1 '. Mothers who were reported as housewife were coded ' 0 ' while farmers and employed mothers were coded ' 1 '. The lowest household income was coded ' 0 ' while the other two levels were coded ' 1 '. Mothers who received infant feeding counselling and delivered in health institution were coded as ' 0 ', their counter parts coded as ' 1 '.

\section{Statistical analysis}

The data were checked for completeness, consistency and cleaned manually. It was entered into EPI Info version 3.5.3.(CDC, Atlanta, Georgia) statistical software and exported to Statistical Package for Social Science (SPSS) research IBM version 20.0 for Window, (IBM SPSS Version 20.0. Armonk, NY: IBM Corp). The descriptive 
finding was presented with tables and graphs. Univariable statistical tests were computed to identify all possible predictor variables. Then the multi-variable logistic regression model was developed considering EBF practice as dependent and those nominee variables selected based on the result of the uni-variable test statistics which had a Wald Statistics with $p$-value $<0.20$. This decision was made based on suggestion to capture all important variables made by Bendel and Afiff [26]. Results are reported as Crude Odds Ratio (COR) or Adjusted Odds Ratio (AOR) with 95 \% Confidence Intervals (CIs). The statistical significance tests was accepted at $p<0.05$.

\section{Ethical approval}

Ethical clearance was obtained from Institute Review Board (IRB) of Debre Berhan University. Permission was granted from Debre Berhan District Health Office and Kebele Administrations. Verbal consent was taken from all mothers who participating in the study.

\section{Results}

A completed data were obtained from 634 mothers and their index infant aged below 12 months. One half, 317 $(50.0 \%)$ of the study subjects were residing in rural kebeles. The majority $(90.5 \%)$ were Christians. One fourth of mothers $(25.7 \%)$ were illiterate, and $9.5 \%$ of husbands were unable to read and write. Close to one third (32.8\%) of mothers were farmers. The majority of mothers $353(55.7 \%)$ were in the age category between 25 and 35 years. The mean age with $( \pm$ SD) of respondent mothers was $30.9( \pm 6.2)$ years, which ranges from 17 to 48 years. The mean $( \pm \mathrm{SD})$ age of the index infants was $7.7 \pm 3.2$ months. In 2014 the lowest daily wage for unskilled government worker in Ethiopia was 19.00 ETB (0.95 USD) which was equivalent to 420.00 ETB (21.00 USD) per month [27]. One third of (34.2\%) households had an income of less than 30.00 USD per month (Table 1).

\section{Maternal, neonatal and child health care services}

Five hundred sixty seven (89.4\%) of mothers had received antenatal care (ANC) services during their last pregnancy. Among mothers 16 (2.8\%) had single visit. $230(40.6 \%)$ had two or three and the rest 321 (56.6\%) had four or more visits. More than one third (36.9\%) were primipara mothers, below half of them (44.2\%) were multipara mothers and the rest $(18.9 \%)$ were grand multipara mothers.

The majority of mothers $(84.4 \%)$ delivered their index infant in the health institutions and were attended by trained health workers. More than one tenth $(12.0 \%)$ of the deliveries were attended by Traditional Birth Attendants (TBAs) and the rest $3.6 \%$ of mothers received delivery assistance from HEWs. Sixty two point six (62.6) per
Table 1 Socio-demographic characteristics of study participants mothers ( $n=634$ ) Debre Berhan District, Ethiopia, April 2014

\begin{tabular}{|c|c|c|}
\hline Characteristics & Frequency & Percentage \\
\hline \multicolumn{3}{|l|}{ Place of residence } \\
\hline Urban & 317 & 50.0 \\
\hline Rural & 317 & 50.0 \\
\hline \multicolumn{3}{|l|}{ Age of mothers (years) } \\
\hline$<25$ & 108 & 17.0 \\
\hline $25-35$ & 353 & 55.7 \\
\hline$>35$ & 173 & 27.3 \\
\hline \multicolumn{3}{|l|}{ Religion } \\
\hline Christian & 574 & 90.5 \\
\hline Muslim & 60 & 9.5 \\
\hline \multicolumn{3}{|l|}{ Educational status of mother respondents } \\
\hline Unable to read and write & 163 & 25.7 \\
\hline Read and write & 180 & 28.4 \\
\hline Elementary school & 105 & 16.6 \\
\hline High school \& preparatory school & 103 & 16.2 \\
\hline Graduate & 83 & 13.1 \\
\hline \multicolumn{3}{|l|}{ Educational status of husband } \\
\hline Unable to read and write & 60 & 9.5 \\
\hline Read and write & 173 & 27.3 \\
\hline Elementary school & 106 & 16.7 \\
\hline High school \& preparatory school & 122 & 19.2 \\
\hline Graduate & 173 & 27.3 \\
\hline \multicolumn{3}{|l|}{ Current working status of respondents } \\
\hline Farmer & 208 & 32.8 \\
\hline Civil servant & 130 & 20.5 \\
\hline Housewife & 125 & 19.7 \\
\hline Merchant & 107 & 16.9 \\
\hline Daily Labourer & 46 & 7.3 \\
\hline Student & 11 & 1.7 \\
\hline House servant (maid) & 7 & 1.1 \\
\hline \multicolumn{3}{|l|}{ Income of the household } \\
\hline Less than 30.00 USD & 217 & 34.2 \\
\hline $30.00-60.00$ USD & 175 & 27.6 \\
\hline Greater than 60.00 USD & 242 & 38.2 \\
\hline \multicolumn{3}{|c|}{ Family size (mean \pm Sd) (Persons/household) } \\
\hline \multicolumn{3}{|l|}{ Sex of infant } \\
\hline Male & 344 & 54.3 \\
\hline Female & 290 & 45.7 \\
\hline \multicolumn{3}{|l|}{ Age of infant (mean $\pm \mathrm{Sd}$ ) in months } \\
\hline
\end{tabular}

NB: ${ }^{*} 1.00$ USD $=19.00 \mathrm{ET}$ Birr 
cent of mothers sought postnatal care after their most recent deliveries. Infant feeding counselling services were received by $82.6 \%$ of mothers during the antenatal and postnatal care services.

\section{Knowledge and attitude of mothers towards EBF}

The majority (97.5\%) of mothers reported that they had ever heard about EBF from one or more sources. The main sources of information for mothers on EBF (90.5\%) were reported as HEWs or Health Workers, followed by mass media (radio or television) (30.4\%). Eighty three per cent of mothers correctly identified the ideal duration of EBF as from birth to six month of life of an infant. The reasons cited by mothers for practicing breastfeeding for infants include: $71.1 \%$ believed it is a societal norm, $29.2 \%$ thought of it as natural gift, and $20.5 \%$ consider breastfeeding as a clean and accessible meal for infants. The majority (89.9 \%) of mothers said they would breastfeed their next infant. Almost all $(97.5 \%)$ mothers encourage their peers to practice EBF. Their main reason for encouraging others were: $68.1 \%$ believe that breastfeeding prevent infection and infant death, $36.9 \%$ recommend it for improving infant wellbeing and $19.6 \%$ recommend it as a cost effective method of infant feeding practice (Table 2).

\section{Practice of mothers towards EBF}

Two thirds, 448 (70.7 \%) of mothers had initiated breastfeeding within one hour while it improved to 488 $(77.0 \%)$ during the first six hours after delivery. Five hundred and five (79.9\%) mothers reported that they fed the colostrum to their index infants. However, 90 (14.2\%) of mothers also reported giving a prelacteal meal for their infants. Of these $53.3 \%$ gave butter, $40.0 \%$ gave a mixture of water with sugar and $6.3 \%$ fed cow's milk to their infants.

Two thirds of mothers 435 (68.6 \% with 95 \% CI: 64.9$72.2 \%)$ had reported practicing EBF for their index infants. Out of 169 mothers who initiated early weaning, the food they provided for their infant before 6 months includes cow's milk (45.0\%), and formula milk (21.3\%). The reason for cessation of EBF for mothers were because they needed to return back to work after completing two months of maternity leave (30.5\%), they believed their breast had insufficient breast milk (23.9\%), they introduced supplementary food to correct poor infant growth for age (13.2\%), had maternal health problem (12.2\%), they thought they had fed for recommended period $(9.1 \%)$ and the rest $8.1 \%$ reported desire of infant for additional meal.

\section{Factors associated with exclusive breastfeeding practice}

In this study we assessed the factors associated with EBF practice of mothers. A univariate logistic regression statistical test was done and the presence of any relationship
Table 2 Knowledge and attitude of mothers $(n=634)$ towards exclusive breastfeeding (EBF), Debre Berhan District, April 2014

\begin{tabular}{|c|c|c|}
\hline Characteristics & Frequency & Percentage \\
\hline \multicolumn{3}{|l|}{ Knowledge } \\
\hline \multicolumn{3}{|l|}{ Ever heard about exclusive breastfeeding } \\
\hline Yes & 618 & 97.5 \\
\hline No & 16 & 2.5 \\
\hline \multicolumn{3}{|l|}{$\begin{array}{l}\text { If you have heard about exclusive } \\
\text { breastfeeding, from whom }(n=618)^{*}\end{array}$} \\
\hline Health Extension Workers / Health Workers & 559 & 90.5 \\
\hline Mass media (radio or television) & 188 & 30.4 \\
\hline Husband & 151 & 24.4 \\
\hline Friends/colleagues & 114 & 18.4 \\
\hline Health Development Army & 60 & 9.7 \\
\hline Community Health Agents & 59 & 9.5 \\
\hline \multicolumn{3}{|l|}{ Ideal time duration for EBF } \\
\hline correct time (6 months) & 529 & 83.4 \\
\hline Incorrect time (less or greater than 6 months) & 105 & 16.6 \\
\hline \multicolumn{3}{|l|}{ Ideal time to wean an infant } \\
\hline correct time (6 months) & 453 & 71.5 \\
\hline Incorrect time & 181 & 28.5 \\
\hline \multicolumn{3}{|l|}{ Attitude } \\
\hline \multicolumn{3}{|l|}{ Why do you breastfeed your infant $(n=634)^{¥}$} \\
\hline An accepted norm to EBF infant & 451 & 71.1 \\
\hline It is natural gift & 185 & 29.2 \\
\hline it is clean and accessible & 130 & 20.5 \\
\hline Easy and cost effective & 68 & 10.7 \\
\hline \multicolumn{3}{|l|}{ Do you want to breastfeed your next baby? } \\
\hline Yes & 519 & 81.9 \\
\hline No & 25 & 3.9 \\
\hline Don't want any more children & 90 & 14.2 \\
\hline \multicolumn{3}{|l|}{ Do you encourage mothers to EBF their infant? } \\
\hline yes & 618 & 97.5 \\
\hline No & 16 & 2.5 \\
\hline \multicolumn{3}{|l|}{$\begin{array}{l}\text { Why do you encourage exclusive } \\
\text { breastfeeding? }(n=634)^{¥}\end{array}$} \\
\hline Prevent infection and infant death & 421 & 68.1 \\
\hline Improve infant's strength & 228 & 36.9 \\
\hline Cost effective & 121 & 19.6 \\
\hline
\end{tabular}

*- sum greater than hundred due to multiple responses

between independent factors with EBF practice of mothers as a dependent variable was examined. The odds of EBF $(p<0.05)$ for rural resident mothers was 3 fold higher (COR 3.13; 95 \% CI: 2.19, 4.47, $p=0.001$ ), 10 fold for mothers aged between 25 and 35 years (COR 10.52; $95 \%$ CI: 5.71, 19.35, $p=0.001$ ), than their counterparts. Women who completed secondary and tertiary education had lower odds of reporting EBF 
practices when compared with their counterparts who were illiterate, COR (95\% CI): $0.38(0.20,0.68)$ and 0.44 (0.24, 0.79), respectively. The Odds of EBF for housewife 1.6 times higher than employed mothers (COR 1.66; 95 \% CI: 1.136, 2.41, $p=0.01$ ), however there was no statistically significant difference with farmers (COR 1.06; $95 \%$ CI: 0.64, 1.75, $p=0.80$ ). The odds of EBF practice was 0.60 times lower among mothers with household income 30 to 60 (USD) than their counterpart mothers with household income less than 30.0 (COR 0.60; 95 \% CI: 0.40, 0.89, $p=0.013$ ). Mothers who did not receive infant feeding counselling (COR 0.47; $95 \%$ CI: 0.31, 0.72, $p=0.001$ ) and did not deliver in the health institution (COR 0.53; $95 \% \mathrm{CI}$ : $0.34,0.83, p=0.005$ ) had lower odds of reporting EBF than those who exhibited these characteristics. Factors like father's educational status, family size, age of infants, sex of infants, birth orders, birth intervals, and parity of mothers didn't reveal statistically significant association $(p>0.05)$ with the EBF practice of mothers.

After identifying the nominee predictor variables of the EBF practice of mothers using univariable logistic regression statistical test, we developed a model to control the possible confounder variables and identified the real predictor variables.

The odds of EBF practice mothers from rural area was 4.54 times higher than urban resident mothers (AOR 4.54; 95 \% CI: 2.64, 7.81, $p=0.001)$. The odds of EBF practice among mothers age 25-35 years and greater or equal to 36 years was up to nine fold (AOR 8.99; $95 \%$ CI: $4.56,17.73, p=0.001$ ) and 3.6 fold (AOR 3.60; $95 \%$ CI: $2.03,6.38, p=0.001$ ) higher than their counterpart mother aged less than 25 years. Mothers who couldn't read and write and who were housewives in occupation had a higher odds of EBF practice than their counterparts respectively $(p=0.001)$. But household income didn't show statistically significant association with EBF practices of mothers $(p>0.05)$ (Table 3$)$.

\section{Discussion}

In this study, it was found that about $97.5 \%$ of mothers had heard about EBF. The majority of mothers $83.4 \%$ correctly knew that the ideal duration of EBF should be from the moment of a child's birth up to the first six months of life. This was higher than the findings of the studies in Kigali, Rwanda, and Kware town of Sokoto State, Nigeria. The first study found $74.4 \%$ of refugee mothers in the urban area [28] and the second study, $31.0 \%$ of women of child bearing age in small town were knowledgeable about the recommended EBF duration [29]. Moreover, a local study conducted in south west Ethiopia had revealed that about two thirds $(67.0 \%)$ of mothers were not knowledgeable on EBF [14]. This could have occurred due to the difference in the infant feeding culture and values of the community.

In this study we found that most $(97.5 \%)$ of the mothers had a positive attitude towards practicing EBF. This was in line with $90.1 \%$ reported from mothers in Saudi Arabia who had a similar attitude towards EBF [17]. This could be attributable to counselling service mothers received on infant feeding at health facilities or at household level [23].

Two thirds $(70.7 \%)$ of mothers have initiated breastfeeding for their infants within one hour after delivery. This report was in line with $72.7 \%$ similar practice in West Nepal [30]. The finding was found higher than the 31 \% documented in Saudi Arabia [17]. Ethiopian Demographic and Health Survey (EDHS, 2011) reported $57 \%$ in urban area versus $51 \%$ in rural area initiating breastfeeding within an hour with the lowest among regions being Amhara Region with $37.5 \%$ [8] and $53 \%$ of mothers initiated breastfeeding within an half an hour time for their newborns in Nigeria [29]. However, this was much lower than the Ethiopian national goal of initiating breastfeeding within one hour for about $92.0 \%$ of newborns, to be achieved by the year 2015 [20].

Mothers were requested by the data collector on their practice on dietary recall for the first six month of life of their index baby and two third (68.6\%) of mothers reported that they exclusively breastfed their infants during the first six months of life. This result was higher than $52.0 \%$ for the nationwide prevalence of EBF documented in EDHS [8], 50.3 \% in Bahir Dar Town [10], $51.9 \%$ in Harer town [12] and $34.4 \%$ in Kigali [28]. Moreover, it was much higher 8.2 to $12.2 \%$ in Saudi Arabia [17, 31], but the finding was lower than the 71.3 \% in Goba, South East Ethiopia [15]. In this study we enrolled all infant age less than 12 months, hence the point estimate might be inflated. Socio-cultural difference on newborns feeding, the intervention made to promote the EBF, and the improved HW assisted delivery might be the main reason for the observed difference in this study. The main reason for cessation of EBF before the age of six months was mothers who need to return back to work $(30.5 \%)$, this finding was similar with the one reported in Southwest Nigeria (24.0\%) [12, 31, 32].

Rural resident have 4.54 time higher chance of practicing EBF for their infant than their counter part urban resident mothers $(P<0.05)$. This finding was in line with the result of the studies where rural residents practiced EBF 1.6 to 2.2 times higher in rural than urban area in Malaysia and Saudi Arabia [31, 32]. This could be explained by the Ethiopian national labour law that grants mothers two months maternity leave. The short maternity leave and the unfavourable work condition to continue EBF might be the cause for early weaning practices of mothers. 
Table 3 Univariate and multivariable logistics regression analysis of socio-demographic and economic variables exclusive breastfeeding in Debre Berhan District, Ethiopia, April 2014

\begin{tabular}{|c|c|c|c|c|c|}
\hline \multirow[t]{3}{*}{ Characteristics } & \multicolumn{2}{|c|}{ Exclusive breastfeeding } & \multirow[t]{3}{*}{ COR $(95 \% \mathrm{Cl})$} & \multirow[t]{3}{*}{ AOR (95 \% Cl) } & \multirow[t]{3}{*}{$p$-value } \\
\hline & Yes & No & & & \\
\hline & N (\%) & N (\%) & & & \\
\hline \multicolumn{6}{|l|}{ Place of residence } \\
\hline Urban & $180(41.4)$ & $137(67.2)$ & 1 & 1 & \\
\hline Rural & $225(58.6)$ & $62(32.2)$ & $3.13(2.19,4.47)$ & $4.54(2.64,7.81)$ & 0.001 \\
\hline \multicolumn{6}{|l|}{ Religion } \\
\hline Christian & $401(92.2)$ & $173(86.9)$ & 1 & 1 & \\
\hline Muslim & $34(7.8)$ & $26(13.1)$ & $0.56(0.32,0.96)$ & $0.75(0.38,1.46)$ & 0.398 \\
\hline \multicolumn{6}{|l|}{ Age of mothers (years) } \\
\hline$<25$ & $47(10.8)$ & $61(30.7)$ & 1 & 1 & \\
\hline $25-35$ & $234(53.8)$ & $119(53.8)$ & $10.52(5.71,19.35)$ & $8.99(4.56,17.73)$ & 0.001 \\
\hline$>35$ & $154(35.4)$ & $19(9.5)$ & $4.12(2.43,6.96)$ & $3.60(2.03,6.38)$ & 0.001 \\
\hline \multicolumn{6}{|l|}{ Educational status of mother } \\
\hline Unable to read and write & $132(30.3)$ & $31(15.6)$ & 1 & 1 & \\
\hline Read and write & $138(31.7)$ & $42(21.1)$ & $0.16(0.09,0.29)$ & $0.06(0.02,0.16)$ & 0.001 \\
\hline Elementary school completed & $68(15.6)$ & 37 (18.6) & $0.21(0.12,0.37)$ & $0.11(0.04,0.28)$ & 0.001 \\
\hline High school completed & $63(14.5)$ & $40(20.1)$ & $0.38(0.20,0.68)$ & $0.22(0.09,0.53)$ & 0.001 \\
\hline Graduate & $34(7.8)$ & $49(24.6)$ & $0.44(0.24,0.79)$ & $0.32(0.16,0.66)$ & 0.002 \\
\hline \multicolumn{6}{|l|}{ Educational status of husband } \\
\hline Unable to read and write & $36(8.3)$ & $24(12.1)$ & 1 & 1 & \\
\hline Read and write & $132(30.3)$ & $41(20.6)$ & $0.98(0.54,1.78)$ & $3.03(1.11,8.24)$ & 0.029 \\
\hline Elementary school completed & $76(17.5)$ & $30(15.1)$ & $0.46(0.28,0.72)$ & $2.09(0.88,5.00)$ & 0.094 \\
\hline High school completed & $88(20.2)$ & $34(17.1)$ & $0.58(0.34,0.97)$ & $1.61(0.70,3.69)$ & 0.254 \\
\hline Graduate & $103(23.7)$ & $70(35.2)$ & $0.57(0.34,0.93)$ & $1.26(0.64,2.48)$ & 0.648 \\
\hline \multicolumn{6}{|l|}{ Current work status of mothers } \\
\hline Housewife & $91(20.9)$ & $34(17.1)$ & 1 & 1 & \\
\hline Working/employed & $190(43.7)$ & $111(55.8)$ & $1.66(1.13,2.41)$ & $0.36(0.18,0.73)$ & 0.005 \\
\hline Farmer & $154(35.4)$ & $54(27.1)$ & $1.06(0.64,1.75)$ & $0.30(0.14,0.64)$ & 0.002 \\
\hline \multicolumn{6}{|l|}{ Household income } \\
\hline Less than 30USD & $160(36.8)$ & $57(28.6)$ & 1 & 1 & \\
\hline $30-60$ USD & $123(28.3)$ & $52(26.1)$ & $0.60(0.40,0.89)$ & $0.61(0.32,1.15)$ & 0.129 \\
\hline Greater than 60 USD & $152(34.9)$ & $90(45.2)$ & $071(0.47,1.08)$ & $1.05(0.58,1.89)$ & 0.858 \\
\hline \multicolumn{6}{|l|}{ Counselled on infant feeding } \\
\hline Yes & $375(86.2)$ & $149(74.9)$ & 1 & 1 & \\
\hline No & $60(13.8)$ & $50(25.1)$ & $0.47(0.31,0.72)$ & $0.42(0.24,0.73)$ & 0.002 \\
\hline \multicolumn{6}{|l|}{ Place of delivery } \\
\hline Health institution & $379(87.1)$ & $156(78.4)$ & 1 & 1 & \\
\hline Home & $56(12.9)$ & $43(21.6)$ & $0.53(0.34,0.83)$ & $044(0.25,0.77)$ & 0.004 \\
\hline
\end{tabular}

NB: In multivariable logistic regression model variables entered: maternal age, religion, place of residence, educational status of mothers, educational status of fathers, occupational status of mothers, household income, infant feeding counselling and place of delivery

Mothers whose age group ranges from 25 to 35 years were nine fold more likely to practice EBF than their counter part mothers who were younger than 25 years $(p<0.05)$. This finding was in agreement with the study in Hareri Regional State, of Ethiopia [12]. This could be due to the fact that younger age mothers do have a better job opportunity and lack the time to EBF their infant. In this study we found that when the educational status 
of mother was to the higher level, their chance of practicing EBF significantly reduced $(p<0.05)$. This could be due to the fact that educated mothers have better job opportunities than illiterate mothers, so they don't have enough time to maintain EBF practice.

Mothers who are housewives were better at practicing EBF than employed mothers or farmers $(p<0.05)$. This result is consistent with study conducted in other parts of Ethiopia namely Bahir Dar and Goba District [10, 15]. A similar finding was documented in Saudi Arabia, Malaysia and Cambodia [31-33]. This could be universal due to the fact that mothers who have more time to be with their infants, have more opportunity to practice EBF than those who do not have due to work or other reasons.

Mothers who have received infant feeding counselling had a much higher adherence to practice EBF for the recommended duration than those mothers who didn't receive the services $(p<0.05)$. There was a similar finding in a study conducted at Bahir Dar [10]. Institutional delivery had a positive association with EBF practice than their counter parts who delivered at home $(p<$ 0.05). Similar report was documented in Bahir Dar and Harer town $[10,12]$. And the main reason could be the access to infant feeding counselling service rather than number of visits.

Unlike other studies, in this study fathers educational status, age of infant, sex of infant, birth interval, birth order, parity of mothers, frequency of antenatal care services, frequency of postnatal care, partner's encouragement and maturity was not found to have a statistically significant relationship with practicing EBF. In other studies, a female infant [16], younger age infant $[10,17]$ and married mothers $[18,19]$ had a higher chance of practicing EBF. The difference could be explained by the existing socio-cultural difference on infant feeding, sex preferences and partners involvement among study participants.

\section{Limitations of the study}

Debre Berhan district is selected using purposive sampling methods so the findings cannot be generalized to other places. Since the study participants are mothers with a child aged less than 12 months, the estimation of EBF practice might be inflated by infant's aged less than 6 months. There is also a possibility of recall bias on provision of prelacteal feeds and identifying the exact time of initiating weaning meals.

\section{Conclusions}

In the studied area the knowledge and attitude of mothers towards EBF was found to be very high. Two third of mothers exclusively breastfed their infants. The main source of health information on EBF was health extension workers. Some of the factors contributing to higher EBF practice identified include being from rural kebele, maternal age greater or equal to 25 years, and housewives significantly adhered to the recommended duration. Moreover, provision of infant feeding counselling during maternal and child health services and delivery in institutions were factors found to be associated with improved EBF practice.

Maintaining access to information on infant feedings using the opportunity during maternal, neonatal and child health services, mass media and community health care system were recommended. Encouraging young, employed and urban resident mothers to practice EBF through counselling and preparing enabling environment is recommended.

\section{Competing interests}

The authors declare that they have no competing interests.

\section{Authors' contributions}

All the authors' are responsible for the design of the research MMA, MDA and ZKK.: MMA supervised the data collection and ensure the quality of collected data. MMA and MDA analysed, interpreted the findings and drafted the manuscript. MDA the corresponding author submitted the paper for publication. All authors reviewed the manuscript and approved the final version.

\section{Acknowledgements}

The author would like to express their gratitude to Debre Berhan University for facilitating the research activity. Funding of this study was provided by Desale Mitiku Asfaw, Fisseha Mitiku Asfaw and Mekonnen Berhane. We are indebted to all data collectors and supervisor's for their dedication and effort during the process. We are obliged to thank all mothers who invested their time and participated in the study for the success of this research. We would take this opportunity to thank Dr. Andualem Assefa Tessema and Shimelis Adugna Bekele for their assitance in editng the manuscript.

\section{Author details}

${ }^{1}$ Addis Ababa City Government Health Bureau, Addis Ketema Sub City Health Department, Addis Ababa, Ethiopia. ${ }^{2}$ Private Health Sector Program, P O Box 2372, Code 1250 Addis Ababa, Ethiopia. ${ }^{3}$ Malaria Consortium, Addis Ababa, Ethiopia.

Received: 4 March 2015 Accepted: 6 August 2015

Published online: 13 August 2015

\section{References}

1. Fund UNC. Committing to Child Survival: A promise renewed progress report 2014. New York: UNICEF; 2014 [http://data.unicef.org/corecode/uploads/ document6/uploaded_pdfs/corecode/APR-2014-170ct14-web_194.pdf].

2. World Health Organization and Child Health Epidemiology Reference Group. Cause specific mortality estimates for major causes of child death for 2000-2013. [http://www.who.int/healthinfo/global_burden_disease/ estimates_child_cod_2013/en/]

3. Federal Minitry of Health. Health and health related indicators 2004 EFY(2011/2012 G.C.). Addis Ababa: Federal Ministry of Health; 2012.

4. Federal Ministry of Health. National strategy for infant and young child feeding (IYCF). Addis Ababa: Family Health Department, Federal Ministry of Health; 2004.

5. Federal Ministry of Health. National strategy for child survival in Ethiopia. Addis Ababa: Family Health Department, Federal Ministry of Health; 2005.

6. World Health Organization. Indicators for assessing infant and young child feeding practice: Part I. Definitions. Conclusions of a consensus meeting held 6-8 November 2007 in Washington D.C., USA. 2008. [http:// whqlibdoc.who.int/publications/2008/9789241596664_eng.pdf?ua=1]

7. Cai X, Wardlaw T, Brown DW. Global Trends in exclusive breastfeeding. Int Breastfeed J. 2012;7:12. 
8. Central Statistical Agency [Ethiopia] and ICF International. Ethiopian demographic and health survey (EDHS) 2011. Addis Ababa, Ethiopia and Calverton, Maryland, USA. 2012

9. Edmond KM, Zandoh C, Quogley MA, Etego SA, Agyei SO, Kirkwood BR Delayed breastfeeding initiation increase risk of neonatal mortality. Pediatrics. 2006;117:e380

10. Seid AM, Yesuf ME, Koye DN. Prevalence of exclusive breastfeeding practice and associated factors among mothers in Bahir Dar town, North West Ethiopia: a community based cross sectional study. Int Breastfeed J. 2013;8:14.

11. Alemayehu T, Haidar J, Habte D. Determinants of exclusive breastfeeding practice in Ethiopia. Ethiopian J Health Dev. 2009;23(1):12-8.

12. Abera K. Infant and young child feeding practice among mothers living in Harer, Ethiopia. Harer Bull Health Sci. 2012;4:66-78.

13. Tamiru D, Mohammed S. Maternal knowledge of optimal breastfeeding practice and associated factors in rural commuity of Arba Minch Zuria. Int J Nutr Food Sci. 2012;2(3):122-9.

14. Tamiru D, Belachew T, Loha E, Mohammed S. Sub-optimal breastfeeding of infants during the first six months and associated factors in rura communities of Jimma Arjo Woreda, Southwest Ethiopia. BMC Public Health. 2012;12:363.

15. Setegn T, Belachew T, Gerbaba M, Deribe K, Deribew A, Biadglign S. Factors associated with exclusive breastfeeding practice among mothers in Goba District, south east Ethiopia: a cross-sectional study. Int Breastfeed J. 2012;7:17.

16. Agho KE, Dibley MJ, Odiasse Jl, Ogbonmwan SM. Determinants of exclusive breastfeeding in Nigeria. BMC Pregnancy Childbirth. 2011;11:2.

17. Al-Binali AM. Breastfeeding knowledge, attitude and practice among school teachers inAbha female educational district, southwestern Saudi Arabia. Int Breastfeed J. 2012;7:10

18. Egeta G, Berhane $Y$, Worku A. Predictors of non-exclusive breastfeeding at 6 months among rural mothers in east Ethiopia: a community based analytical cross- sectional study. Int Breastfeed J. 2013;8:8.

19. Mannion CA, Hobbs AJ, McDonald SW, Tough SC. Maternal perceptions of partner support during breasfeeding. Int Breastfeed J. 2013:8:4

20. Federal Minitry of Health. Health sector development program IV (2010/ 2011 to 2014/2015). Addis Ababa: Federal Ministry of Health; 2010.

21. Argaw $H$. The health extension program of Ethiopia. Summary of concepts, progress, achievements and challenges. Addis Ababa: WHO Country Office of Ethiopia; 2007.

22. Centre for National Health Development in Ethiopia. Assessment of working conditions of the first batch of health extension workers. Addis Ababa: The Earth Institute at the Colombia University; 2005.

23. Bekele T, Rasschart F, Assefa Y, Berhe A, Damme WV. Disease control program contribution to health system strengthening: good practice and new approaches for scale-up. Addis Ababa. Antewerp: Federal Ministry of Health of Ethiopia and the Institute of Tropical Medicine; 2011.

24. Debre Berhan District Health Office. Annual review meeting report. Debre Berhan: Debre Berhan District Health Office; 2005 EFY (2012/2013 G.C).

25. Bartlett JE, Kotrlik JW, Higgins CC. Organizational research: Determining appropriate sample size in survey research. Inform Technol Learn Perform J. 2001;19(1):43-50.

26. Bendel RB, Afifi AA. Comparison of stopping rules in forward regression. J Am Stat Assoc. 1977;72(357):46-53.

27. Mywage.Org/Ethiopia. [http://www.mywage.org/ethiopia/home/salary/ minimum-wages]

28. Jino $G B$, Munyanshongone C, Birungi F. Knowledge, attitude and practice of exclusive breast-feeding of infants aged 0-6 months by Urban Refugee Women in Kingali. Rwanda Med J. 2013;70:7-10.

29. Oche MO, Umar AS, Ahmed $\mathrm{H}$. Knowledge and practice of exclusive breastfeeding in Kware, Nigeria. Afr Health Sci. 2011;11(3):518-23.

30. Chandrashekhar TS, Joshi HS, Binu VS, Shankar PR, Rana MS, Ramachandran $U$. Breast-feeding initiation and determinants of exclusive breastfeeding- a questionnaire survey in an urban population of western Nepal. Public Health Nutr. 2007;10(2):192-7.

31. El-Gilany AH, Shady E, Helal R. Exclusive breastfeeding in Al-Hassa, Saudi Arabia. Breastfeed Med. 2011;6(4):209-13.

32. Tan KL. Factor associated with exclusive breastfeeding among infants under six months of age in Peninsular Malaysia. Int Breastfeed J. 2011;6:2.

33. Sasaki Y, Ali M, Kakimoto K, Saoeun O, Kanal K, Kuroiwa C. Predictors of exclusive breast-feeding in early infancy: a survey report from Phnom Penh,Cambodia. J Pediatr Nurs. 2010;25(6):463-9.

\section{Submit your next manuscript to BioMed Central and take full advantage of:}

- Convenient online submission

- Thorough peer review

- No space constraints or color figure charges

- Immediate publication on acceptance

- Inclusion in PubMed, CAS, Scopus and Google Scholar

- Research which is freely available for redistribution

Submit your manuscript at www.biomedcentral.com/submit 